relationship of HbA1c levels with OSA severity in both diabetic and non-diabetic patients.

Results In a cohort of predominantly male (63.5\%) and severely obese (mean BMI $40.3 \mathrm{~kg} / \mathrm{m}^{2}$ ) individuals, 32.2\% had T2DM. Although the likelihood of T2DM was significantly greater in the highest AHI quartile than the lowest (unadjusted OR 1.78; 95\% CI: 1.29-2.47), this relationship lost significance following adjustment for anthropometric, demographic, and clinical factors (adjusted OR 1.21; 95\% CI: 0.83-1.76; p = 0.33). However, severity of nocturnal hypoxaemia remained a predictor of T2DM prevalence despite adjustment for confounding factors (adjusted OR for most severe mean nocturnal $\mathrm{SpO}_{2}$ quartile 2.23; 95\% CI: $1.50-2.20 ; \mathrm{p}<0.001)$, as well as predicting the likelihood of poor diabetic control (adjusted OR 1.87; 95\% CI: 1.06-3.30; $\mathrm{p}=0.03$ ). In further analyses, HbA1c levels were independently predicted by OSA severity indices and nocturnal hypoxaemia in both non-diabetic and diabetic subjects, while adjusted mean HbA1c levels were significantly higher in patients with more severe sleep disordered breathing.

Conclusion Metabolic health in severely obese sleep patients appears to be significantly worse in those subjects with more severe sleep disordered breathing, with a particularly strong relationship with the degree of nocturnal hypoxaemia.

\section{S23 NEURAL RESPIRATORY DRIVE DURING SLEEP AT HIGH ALTITUDE}

${ }^{1} \mathrm{~J}$ Steier, ${ }^{2} \mathrm{~N}$ Cade, ${ }^{1} \mathrm{~B}$ Walker, ${ }^{1} \mathrm{~J}$ Moxham, ${ }^{1} \mathrm{CJ}$ Jolley. ${ }^{1}$ King's College London, London, UK; ${ }^{2}$ Francis Crick Institute, London, UK

\subsection{6/thoraxjnl-2016-209333.29}

Introduction Ventilation at altitude changes due to altered levels of pO2, pCO2 and the effect on blood $\mathrm{pH}$. Nocturnal ventilation is particularly exposed to these changes. We hypothesised that increasing neural respiratory drive is associated with the severity of sleep-disordered breathing at altitude.

Subjects and methods British mountaineers were studied at sea level (London, UK), and at altitude at the Aconcagua (Andes, Argentina). Neural respiratory drive (NRD) was measured as electromyogram of the diaphragm (EMGdi) overnight by a transoesophageal multi-electrode catheter (Yinghui Medical Ltd, Guangzhou, China). Following initial assessment with a polysomnography (London, UK), pulse oximetry measured oxygen concentration and oxygen desaturation indices (4\%ODI) at altitude.

Results Four healthy subjects (3male, age 31 (3) years, bodymass-index $23.6(0.9) \mathrm{kg} / \mathrm{m}^{2}$, neck circumference $37.0(2.7) \mathrm{cm}$, $\mathrm{FEV}_{1} 111.8$ (5.1)\% predicted, FVC 115.5 (6.3)\% predicted) were studied. Inspiratory and expiratory muscle strength were normal (PImax 130.7 (29.8) cm $\mathrm{H}_{2} \mathrm{O}$, PEmax (153.3 (38.4) cm $\mathrm{H}_{2} \mathrm{O}$ ). No subject had significant sleep abnormalities at sea level (Total Sleep Time 344.4 (30.5) mins, Sleep Efficiency 86.6 (6.4)\%, Respiratory Disturbance Index 0.8 (0.4)/hour, mean $\mathrm{SpO}_{2} 97.5$ (1.3\%). The oxygen desaturation index increased with the development of periodic breathing at altitude (4\% ODI 22.0 (7.2)/hour at $3,380 \mathrm{~m}, 61.4(26.9) /$ hour at $4,370 \mathrm{~m})$. Average nocturnal SpO2 $(84.8(0.5 \%))$ at $3,380 \mathrm{~m} ; 81.0(4.1 \%)$ at $4,370 \mathrm{~m})$ and nadir oxygenation $(68.1(8.6 \%)$ at $3,380 \mathrm{~m} ; 67.4(7.6 \%)$ at $4,370 \mathrm{~m})$ dropped with altitude. The average EMGdi was 5.2 (19.1\%) max at sea level and increased to 14.1 (3.4\%) at altitude when falling asleep at $4,370 \mathrm{~m}$, and correlated well with the $4 \%$ ODI $(r=0.968, p=0.032)$. EMGdi during the last inspiratory effort prior to central apnoea was $5.1(1.5 \%)$ max, while the first inspiratory effort following central apnoea was 10.5 (3.2\%) max at $4,370 \mathrm{~m}$.

Conclusion The severity of periodic breathing when asleep deteriorates with an increase in altitude, induced by an elevated neural respiratory drive as a response to hypobaric environmental conditions.

\section{S24 A COMPARISON OF PULSE TRANSIT TIME BETWEEN SUBJECTS WITH OBSTRUCTIVE SLEEP APNOEA SYNDROME, NOCTURNAL INSPIRATORY FLOW LIMITATION AND THE ABSENCE OF SIGNIFICANT SLEEP DISORDERED BREATHING}

${ }^{1} \mathrm{~B}$ Chakrabarti, ${ }^{2} \mathrm{~S}$ Emegbo, 'S Craig, ${ }^{1} \mathrm{~N}$ Duffy, ${ }^{1} \mathrm{JF}$ O'Reilly. 'Aintree Chest Centre, Liverpool, UK; ${ }^{2}$ Liverpool Sleep and Ventilation Centre, Liverpool, UK

\subsection{6/thoraxjnl-2016-209333.30}

Introduction Pulse Transit Time (PTT) represents a non-invasive indirect marker of sleep fragmentation in OSAS. Little is known regarding PTT indices in persons presenting with sleepiness where sleep studies exhibit "flow limited" breaths in the absence

Abstract S24 Table 1 Key demographics in the IFL, OSAS and NFL "Control" cohorts

\begin{tabular}{|c|c|c|c|c|c|}
\hline & $\begin{array}{l}\text { Inspiratory flow limitation (IFL) } \\
\text { cohort } \\
(\mathrm{n}=20 \text {; female }=13 \text { ) }\end{array}$ & $\begin{array}{l}\text { Obstructive sleep apnoea syndrome (OSAS) } \\
\text { Cohort } \\
(\mathrm{n}=20 \text {; female }=13)\end{array}$ & $\begin{array}{l}\text { "NFL" } \\
\text { Control group }(n=20 \text {; } \\
\text { female = 13) }\end{array}$ & f Value & $P$ value \\
\hline Age (years) & $47(8.39)$ & $45(8.30)$ & 47 (8.79) & $F=0.28$ & $P=0.76$ \\
\hline $\begin{array}{l}\text { BMl } \\
(\mathrm{kg} / \mathrm{m} 2)\end{array}$ & $34.25(6.63)$ & $36.31(5.62)$ & $28.90(6.81)$ & $\mathrm{F}=7.21$ & $P=0.002$ \\
\hline $\begin{array}{l}\text { AHI } \\
\text { (per hour) }\end{array}$ & $3.84(1.16)$ & $48.93(16.77)$ & $1.01(1.05)$ & $F=152.78$ & $P<0.001$ \\
\hline $\begin{array}{l}\text { RDI } \\
\text { (per hour) }\end{array}$ & $17.71(5.34)$ & $57.22(16.33)$ & $2.63(1.34)$ & $F=159.72$ & $P<0.001$ \\
\hline Oxygen Saturation & $95.05(1.85)$ & $93.75(1.55)$ & $95.90(1.48)$ & $F=10.14$ & $P<0.001$ \\
\hline $\begin{array}{l}\text { Epworth Sleepiness Score (ESS) at } \\
\text { presentation }\end{array}$ & $16.35(3.65)$ & $14.45(5.52)$ & $7.90(6.21)$ & $F=12.49$ & $P<0.001$ \\
\hline Presence of Hypertension & $5 / 20$ & $5 / 20$ & $0 / 20$ & $F=3.16$ & $P=0.05$ \\
\hline Presence of Cardiac Disease & $1 / 20$ & $1 / 20$ & $0 / 20$ & $\mathrm{~F}=0.5$ & $P=0.61$ \\
\hline
\end{tabular}


of clinically significant OSA (a so called Inspiratory "Flow Limitation" (IFL) cohort) and whether PTT indices differ when compared to OSAS subjects and with a "control" group exhibiting no evidence of OSAS or IFL ("Non-Flow Limited" or NFL cohort). Methodology 20 subjects meeting criteria for the IFL cohort (mean AHI $=3.84 / \mathrm{hr} ; \mathrm{RDI}=17.71 / \mathrm{hr}$ ) were aged $( \pm 2 \mathrm{yrs})$ and gender matched with 20 OSAS subjects (mean AHI $=48.93 \mathrm{hr}$ ) and 20 control "NFL" subjects (no sleep disordered breathing; mean $\mathrm{AHI}=1.01 / \mathrm{hr}$; RDI $=2.63 / \mathrm{hr}$ ) underwent respiratory limited polysomnography, including pulse oximetry and ECG monitoring. PTT was defined as interval between the electrocardiographic $\mathrm{R}$ wave and point corresponding to $50 \%$ height of the ascending plethysmographic (pulse) waveform; PTT arousal (deceleration) defined by decline in PTT signal of $\geq 15$ ms, lasting 5 seconds; PTT Deceleration index (PTT Di) defined by number of PTT arousals per hour.

Results Table 1 outlines key demographics in the cohorts. Of the NFL cohort, 14 presented with snoring in absence of sleepiness. $72 \%$ and $84 \%$ were deemed "responders" to CPAP within the IFL and OSAS cohorts respectively. The PTT DI in the IFL cohort $(33.67 \pm(23.34) / \mathrm{hr})$ was significantly higher than that measured in the control NFL cohort $(23.89 \pm(18.88) / \mathrm{hr})$ but significantly lower than that measured in the OSAS cohort $(55.21$ $\pm(29.30) / \mathrm{hr} ; 3$-way ANOVA; F $=8.76$; $\mathrm{p}<0.001)$. PTT Di was positively correlated with AHI within the whole study population ( $\mathrm{CC}=0.46 ; \mathrm{p}<0.001)$. Within the IFL cohort, PTT Di was positively correlated with age $(\mathrm{CC}=0.501 ; \mathrm{p}=0.024)$ but not with gender and BMI.

Conclusion The PTT Deceleration Index increased proportionately with SDB, with significantly higher markers of arousal in sleepy subjects exhibiting nocturnal IFL in comparison to control subjects, but not as high as those with clinically significant OSA. These findings support the relevance of IFL as a potentially significant pathogenic entity in the development of daytime sleepiness. The utility of PTT Deceleration Index as a therapeutic target for CPAP Titration in OSAS requires further evaluation.

\section{S25 SURVEY OF THE NEW DRIVER AND VEHICLE LICENSING AUTHORITY (DVLA) GUIDANCE FOR OBSTRUCTIVE SLEEP APNOEA (OSA): UK SLEEP CENTRES OPINION}

EL Palmer, S West. Freeman Hospital, Newcastle upon Tyne, UK

\subsection{6/thoraxjnl-2016-209333.31}

Introduction and objectives The DVLA produced new guidelines 'Assessing Fitness to Drive - a guide for medical professionals' in March 2016. An online survey was designed to seek opinion about the guidance relating to patients with OSA, which was completed in May 2016.

Methods An anonymous online survey was designed and the survey link emailed to staff at UK sleep centres, identified from addresses held by the ARTP, BSS and SATA. It could be completed by any member of the sleep team, or more than one member. Responses were collated centrally.

Results There were 204 survey respondents, representing sleep centres of different sizes $(<500$ CPAP users to $>10,000)$. They included physiologists, consultants and nurses. $77 \%$ were aware the DVLA had produced new guidelines. Only 2\% stated they had received communication from the DVLA about the changes. $75 \%$ did not find the new guidance for OSA easy to follow.
$62 \%$ of responders said the guidelines will cause confusion for patients and potentially stop them coming forward for treatment. $33 \%$ were unclear what advice to give to their patients.

The majority defined 'excessive sleepiness' based on symptoms (80\%), including Epworth Sleepiness Score (ESS) >9 (28\%) or $>12(56 \%)$. Only 19 people (10\%) felt that apnoea-hypopnea index $(\mathrm{AHI})>5$ or oxygen desaturation index (ODI) $>5$ contributed to their assessment of patients' sleepiness. $87 \%$ did not think AHI or ODI was a good way to assess a patient's ability to drive.

$72 \%$ of responders said the suggested frequency of follow-up appointments would increase their workload. $41 \%$ said their service did not have sufficient capacity to meet guidance for confirming adherence to treatment in group 2 drivers. $45 \%$ said their service could not meet the guidelines for reviewing symptoms and treatment compliance in patients with moderate/severe OSA with excessive sleepiness.

Conclusions The new DVLA guidelines for OSA are difficult to follow for the majority of sleep professionals. These guidelines may prevent patients coming forward for assessment and treatment and will stretch the capacity of many already overworked sleep services. The guidelines require urgent further review by the DVLA and discussion with sleep experts in the UK.

\section{S26 FEASIBILITY AND PATIENT TOLERABILITY OF TRANSCUTANEOUS ELECTRICAL STIMULATION IN OBSTRUCTIVE SLEEP APNOEA}

${ }^{1} \mathrm{KI}$ Reed, ${ }^{1} \mathrm{MF}$ Pengo, ${ }^{1} \mathrm{~S}$ Xiao, ${ }^{1} \mathrm{C}$ Ratneswaran, ${ }^{1} \mathrm{~N}$ Shah, ${ }^{1} \mathrm{~T}$ Chen, ${ }^{1} \mathrm{~A}$ Douiri, ${ }^{1} \mathrm{~N}$ Hart, ${ }^{2} Y$ Luo, ${ }^{1} \mathrm{GF}$ Rafferty, ${ }^{2} \mathrm{GP}$ Rossi, ${ }^{1} \mathrm{~A}$ Williams, ${ }^{3} \mathrm{Ml}$ Polkey, ${ }^{1} \mathrm{~J}$ Moxham, ${ }^{1} \mathrm{I}$ Steier. ${ }^{1} \mathrm{King}$ 's College London, London, UK; ${ }^{2}$ Department of Medicine, Padua, Italy; ${ }^{3} / m p e r i a l$ College London, London, UK

\subsection{6/thoraxjnl-2016-209333.32}

Introduction Transcutaneous electrical stimulation (TES) provides neuromuscular tone to the pharyngeal dilator muscles of the upper airway (UA) while asleep, but feasibility of this method to treat obstructive sleep apnoea (OSA) throughout the whole night has not been tested.

Patients and methods We conducted a phase two double-blind, sham-controlled, randomised controlled trial using TES of the UA muscles in 36 patients with confirmed OSA to assess patients' device acceptance and the side effect profile. Patients were studied using polysomnography during randomly assigned nights of sham-stimulation and active treatment following titration of the current while awake. Assessment of patients' device acceptance and experience of side effects was measured using a visual analogue scale ( $0-10$ points) where high scores indicated better outcomes.

Abstract S26 Table 1 Device acceptance and side effect profile of TES and polysomnography data. Variables presented as median and interquartilerange. $p$-value derived from the Wilcoxon test.

\begin{tabular}{llll}
\hline Parameters & Sham- Stimulation & Active treatment & p-value \\
Feeling refreshed & $5.7(2.7-7.2)$ & $6.6(2.2-8.5)$ & 0.40 \\
Skin discomfort & $9.9(9.5-10.0)$ & $9.9(9.7-10.0)$ & 0.95 \\
Tongue unpleasant sensation & $9.9(9.4-10.0)$ & $9.9(9.4-10.0)$ & 0.63 \\
Sleep quality & $5.6(2.9-7.1)$ & $6.4(2.4-8.0)$ & 0.28 \\
Morning headache & $9.4(6.3-10.0)$ & $9.9(8.1-10.0)$ & 0.27 \\
Mouth dryness & $4.4(2.2-8.5)$ & $7.4(4.9-9.7)$ & 0.007 \\
\hline
\end{tabular}

